\title{
PENERAPAN METODE ANALYTICAL HIERARCHY PROCESS (AHP) UNTUK MENENTUKAN SUPPLIER IKAN TERI (Studi Kasus di PT. Urchindize Indonesia)
}

\author{
Mufidah Ulwiyatun Nafisah, Noor Nailie Azzat \\ Fakultas Sains dan Teknologi UNISNU Jepara \\ mufidahun@gmail.com, nailie@unisnu.ac.id
}

\begin{abstract}
PT Urchindize has more than 35 anchovy suppliers, although the company has many suppliers, it still often encounters obstacles. The obstacle felt by the company is that the supplier has not been able to meet a number of standard criteria owned by the company. The company has not yet implemented the proper selection and assessment method for suppliers. Based on this, the company must select suppliers to get suppliers who are truly able to meet company needs consistently and with quality. Based on the results of data processing using the Analytical Hierarchy Process (AHP) method, obtained the most influential criteria in supplier selection in the following order of priority: price criteria, delivery criteria, quality criteria, supplier relationship criteria, service criteria and responsibility. While the right supplier in the selection of suppliers for PT. Urchindize namely Mr. Ali Yudin became the main priority with a weight of 0.181 , second was Mr. Akhsan with a weight of 0.159 , third was Mr. Sugiyanto with a weight of 0.141 , fourth was Mr. Junaidi with a weight of 0.118 , the fifth was Mr. Masdawi with a weight of 0.102 , the sixth was is Mrs. Mustarikah with a weight of 0.081 , seventh is Mr. Sofyan and Mr. Idris with a weight of 0.073 , eighth is Mr. Yusman with a weight of 0.044 , the last priority is Mr. Abdul Rokhman with a weight of 0.037 .
\end{abstract}

Keywords: supplier, selection, AHP

\begin{abstract}
Abstrak
PT Urchindize memiliki lebih dari 35 supplier ikan teri, walaupun perusahaan memiliki banyak supplier, akan tetapi masih sering kali menemukan kendala. Kendala yang dirasakan oleh perusahaan adalah supplier belum bisa memenuhi beberapa standard kriteria yang dimiliki pihak perusahaan. Perusahaan belum melaksanakan metode pemilihan dan penilaian yang tepat terhadap supplier. Berdasarkan hal tersebut, maka perusahaan harus menyeleksi supplier untuk mendapatkan supplier yang benar-benar mampu memenuhi kebutuhan perusahaan secara konsisten dan berkualitas. Berdasarkan hasil pengolahan data dengan menggunakan metode Analytical Hierarchy Process (AHP), didapatkan kriteria yang paling berpengaruh dalam pemilihan supplier dengan urutan prioritas sebagai berikut: kriteria harga, kriteria pengiriman, kriteria kualitas, kriteria hubungan supplier, kriteria pelayanan dan tanggung jawab. Sedangkan supplier yang tepat dalam pemilihan supplier bagi PT. Urchindize yaitu Pak Ali Yudin menjadi prioritas utama dengan bobot sebesar 0,181, kedua adalah Pak Akhsan dengan bobot sebesar 0,159, ketiga adalah Pak Sugiyanto dengan bobot sebesar 0,141, keempat adalah Pak Junaidi dengan bobot sebesar 0,118, kelima adalah Pak Masdawi dengan bobot sebesar 0,102, keenam adalah Bu Mustarikah dengan bobot sebesar 0,081, ketujuh adalah Pak Sofyan dan Pak Idris dengan bobot sebesar 0,073, kedelapan adalah Pak Yusman dengan bobot sebesar 0,044, prioritas terakhir adalah Pak Abdul Rokhman dengan bobot sebesar 0,037 .
\end{abstract}

Kata kunci: pemilihan, supplier, AHP

\section{PENDAHULUAN}

Kompetisi bisnis yang semakin selektif menuntut perusahaan harus merancang strategi dan membuat taktik bisnis secara tepat. Persaingan yang ketat antara pelaku bisnis membuat perusahaan saling berlombalomba untuk memberikan kualitas terbaik untuk dapat bersaing. 
PT. Urchindize bergerak di bidang eksport hasil laut, produk utama dari PT. Urchindize adalah ikan teri nasi. PT. Urchindize saat ini mayoritas dipasok oleh supplier dalam negeri. Hasil pengolahan ikan teri nasi mengarah pada pasar internasional. PT Urchindize memiliki lebih dari 35 supplier ikan teri walaupun perusahaan memiliki banyak supplier akan tetapi masih sering kali menemukan kendala yang terjadi pada bahan baku.

Kendala yang kadang terjadi saat proses produksi yaitu kelalaian dari supplier yang berdampak pada jalannya produksi ataupun produk. PT Urchindize memilih supplier hanya berdasarkan kebutuhan saja tanpa menggunakan metode yang tepat bagi dalam pemilihan dan penilaian supplier sehingga perusahaan tersebut tidak memperhitungkan biaya, kualitas, ketepatan pengiriman, pelayanan, tanggung jawab dan pengalaman perusahaan supplier tersebut.

Pentingnya supplier sebagai pemasok bahan baku produksi membuat perusahaan lebih selektif dalam melakukan pemilihan dan penilaian kinerja supplier sebagai rekan bisnis yang perusahaan miliki. Dalam mendapatkan keputusan pemilihan supplier, perusahan sebagai pemilik keputusan akan membutuhkan alat analisis yang mengharuskan perusahaan untuk memecahkan suatu masalah yang bersifat kompleks sehingga keputusan yang diambil lebih berkualitas. Salah satu metode yang digunakan untuk pengambilan keputusan dengan ranking bobot dari masing-masing alternatifnya. Berdasarkan penelitian tesrsebut penulis melakukan penelitian tugas akhir di PT. Urchindize tentang pemilihan supplier ikan teri nasi menggunakan metode Analytical Hierarchy Process (AHP). Menurut Reny Rahmayanti (2010) Analytical Hierarchy Process (AHP) adalah metode pengambilan keputusan yang dikembangkan untuk pemberian prioritas pada beberapa alternatif ketika masing-masing kriteria harus dipertimbangkan, serta memperbolehkan pengambil keputusan untuk menyusun masalah yang kompleks dalam suatu bentuk hirarki atau beberapa level yang terintegrasi. Pada proses pengolahan data berupa proses perhitungan bobot dan uji konsistensi menggunakan software Microsoft Excel. Di mana Microsoft Excel berguna sebagai analisis pengambil keputusan.

Dengan menggunakan metode AHP, diharapkan PT. Urchindize dapat menyeleksi dan mengevaluasi supplier sehingga perusahaan dapat menentukan alternatif supplier yang sesuai dengan kriteria yang diinginkan. Setelah dilakukan proses penyeleksian supplier, perusahaan dapat memonitoring kinerja supplier terpilin secara berkelanjutan.

\section{TINJAUAN PUSTAKA}

\section{Pengertian Supplier}

Indrajit, dkk (2016) menyatakan dalam bukunya bahwa supplier adalah penyedia bahan baku ataupun barang jadi bagi perusahaan. Supply chain management (SCM) yang baik diperlukan informasi yang lancar, transparan serta akurat dan kepercayaan antar bagian pengadaan barang dan jasa. Maka dari itu hubungan antara mereka semacam rekan kerja. Salma (2018) berpendapat bahwa, rekan kerja adalah suatu solusi yang baik dalam mencapai optimalisasi supply chain management.

\section{Pemilihan Supplier}

Menurut Pujawan dan Erawan (2010) proses pemilih supplier merupakan kegiatan yang strategis terutama apabila supplier tersebut memasok benda atau item yang penting dan yang digunakan dalam waktu panjang. Pemilihan pemasok yang salah, dapat merugikan perusahaan. Untuk itu pemilihan supplier merupakan komponen penting yang harus dilakukan dalam suatu perusahaan.

\section{Analytic Hierarchy Process (AHP)}

Menurut Thomas end Luis (2012) Analytic Hierarchy Process (AHP) adalah pendekatan dasar untuk pengambilan keputusan. Ini dirancang untuk mengatasi rasional dan intuitif untuk memilih yang terbaik dari sejumlah alternatif yang dievaluasi sehubungan dengan beberapa kriteria. Dalam proses ini, pembuat keputusan melakukan penilaian perbandingan berpasangan sederhana yang kemudian digunakan untuk mengembangkan prioritas keseluruhan untuk menentukan peringkat alternatif. 
Menurut Tio (2018) ada 4 prinsip dasar yang digunakan untuk memecahkan masalah AHP ini, yaitu:

1. Decomposition (Dekomposisi)

2. Comparative Judgement (Perbandingan penilaian)

3. Synthesis of Priority (Sintesis Prioritas)

4. Logical Consistency

Untuk mendapatkan keputusan yang rasional dengan menggunakan metode Analytic Hierarchy Process (AHP), perlu dilakukan beberapa tahapan di antaranya:

1. Mendefenisikan masalah dan menentukan solusi.

2. Menetapkan kriteria dan subkriteria.

3. Menyusun struktur hirarki masalah.

4. Membuat matrik perbandingan berpasangan.

5. Penentuan bobot atau prioritas.

Langkah-langkah dalam menentukan bobot atau prioritas adalah:

a. Pembuatan matrik perbandingan berpasangan (Comparison Matrix).

Tabel 1. Matriks Perbandingan Berpasangan

\begin{tabular}{|c|c|c|c|c|}
\hline C & $\mathrm{A} 1$ & $\mathrm{~A} 2$ & A3 & $\mathrm{An}$ \\
\hline $\mathrm{A} 1$ & 哈 & $\frac{112}{a 12}$ & $\frac{7+\sqrt{3}}{a 13}$ & $\Rightarrow \bar{A}$ \\
\hline A2 & 窟i & $\begin{array}{l}\frac{\partial-12}{a_{12}} \\
\beta_{222}\end{array}$ & $\begin{array}{l}3 . \\
a_{2 a}^{2 a}\end{array}$ & $\frac{a n}{2 a n}$ \\
\hline A3 & $\begin{array}{l}a_{21} \\
a_{a x}\end{array}$ & $\frac{a_{22}}{a_{a z}}$ & $\begin{array}{l}a^{2 a} \\
a^{2 a \lambda}\end{array}$ & $\begin{array}{l}a_{2 n} \\
a^{2 n}\end{array}$ \\
\hline $\mathrm{An}$ & 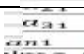 & $\frac{a^{22}}{8 n 2}$ & 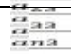 & 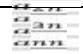 \\
\hline
\end{tabular}

Sumber: Salma (2018)

b. Normalisasi data kuesioner.

Normalisasi yang dilakukan adalah dengan membagi hasil kuesioner dengan total hasil per baris.

$$
\text { Nor }=\frac{\text { Hasil kuesioner }}{\text { Tot hasil per baris }}
$$

c. Menghitung total weight matrix

Total weight matrix merupakan hasil penjumlahan hasil normalisasi data dari setiap kolom yang ada.

\section{d. Menghitung eigen vector}

Menghitung bobot atau prioritas dengan cara hasil dari perhitungan total weight matrix dibagi dengan jumlah total weight matrix.

$$
w_{i}=\frac{\text { Total Weight Matrix }}{\sum \text { Total Weight Matrix }}
$$

e. Melakukan perhitungan perkalian matrix (weight sum vector)

Perkalian matriks pada penelitian kali ini dengan cara mengalikan antara hasil kuesioner dengan eigen vector.

$$
W S V=\sum_{1}^{n}=1 a_{11 \times w_{i}}
$$

f. Menentukan nilai eigen value

$$
\lambda=\frac{W S V}{w i}
$$

g. Menghitung nilai lamda max

$$
\lambda \operatorname{Max}=\frac{\text { Eeigen value }}{\sum \text { Weight matrix }}
$$

6. Uji Konsistensi

a. Menghitung nilai index konsistensi

$$
C L=\frac{\lambda \max -n}{n-1}
$$

b. Menghitung Nilai Rasio Konsistensi

$$
C R=\frac{C L}{R I}
$$

Metode AHP digunakan untuk mengelolah data dari responden ahli, namun pada metode pemilihan supplier ini dilakukan oleh beberapa responden ahli (Kelompok). Bobot tersebut didapatkan dari rata-rata geomatrik (Geomatric Mean) dari penilaian beberapa responden ahli (kelompok), dirumuskan dengan:

$$
G M=\frac{x 1+x 2+x n}{n}
$$

\section{METODE PENELITIAN}

Metodologi penelitian berisi mengenai langkah-langkah yang dilakukan dalam penelitian. Pada penelitian ini, metodologi penelitian ditunjukan pada Gambar 1. 


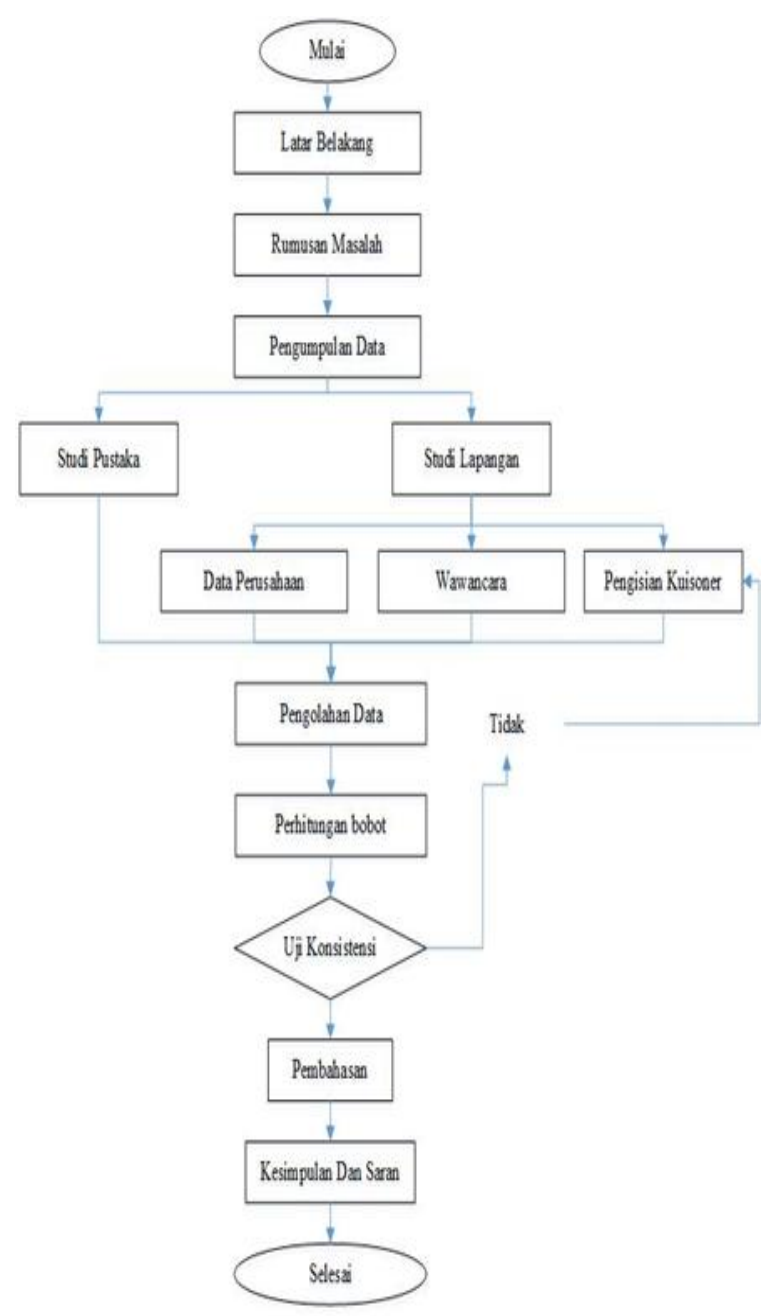

Gambar 1. Diagram Alur Penelitian

\section{ANALISIS DATA DAN PEMBAHASAN \\ Pengumpulan Data}

Pengumpulan data menjelaskan tentang proses pengumpulan data serta data-data yang digunakan untuk kepentingan penelitian ini yaitu prosedur penerimaan supplier, metode pemilihan supplier, menentukan supplier yang paling tepat untuk perusahaan dengan metode Analytical Hierarchy Process (AHP).

\section{Prosedur Penerimaan Supplier}

Langkah-langkah perusahaan dalam mendapatkan supplier baru adalah sebagai berikut:

a. Relasi kerja antara perusahaan dan pemasok.

b. Iklan dari pemasok bahan baku.

\section{Metode Pemilihan Supplier}

Metode pemilihan supplier terbaik yang dilakukan oleh PT. Urchindize ini berdasarkan kontinuitas supplier dalam mengirimkan bahan baku kepada pihak perusahaan. Berdasarkan kontinuitas pengiriman bahan baku yang dijadikan sebagai perbandingan pemilihan supplier terbaik bagi PT. Urchindize, sepuluh supplier tersebut diantaranya adalah:
1. Pak Akhsan
6. Bu Mustarikah
2. Pak Ali Yudin
7. Pak Sofyan
3. Pak Sugiyanto
8. Pak Idris
4. Pak Junaidi
9. Pak Yusman
5. Pak Masdawi
10. Pak Abdul Rokhim

\section{Analisis Data}

\section{Menetapkan Kriteria dan Subkriteria}

Menurut Jay dan Render (2015) mengatakan biasanya terdapat sejumlah kriteria yang mempunyai efek pada pemilihan supplier misalnya kualitas produk, kecepatan pengiriman, kendala pengiriman, pelayanan pelanggan dan kinerja keuangan. Pada penelitian ini terdapat 6 kriteria dan 14 subkriteria yang digunakan dalam penelitian ini. Penetapan kriteria dan subkriteria didapatkan dari jurnal dan skripsi lalu dilakukan proses diskusi bersama dengan pihak perusahaan atau ahli.

\section{Struktur Hirarki Masalah}

Berikut adalah struktur hirarki masalah dalam pemilihan supplier ikan teri di PT. Urchindize seperti pada Gambar 2 berikut. 


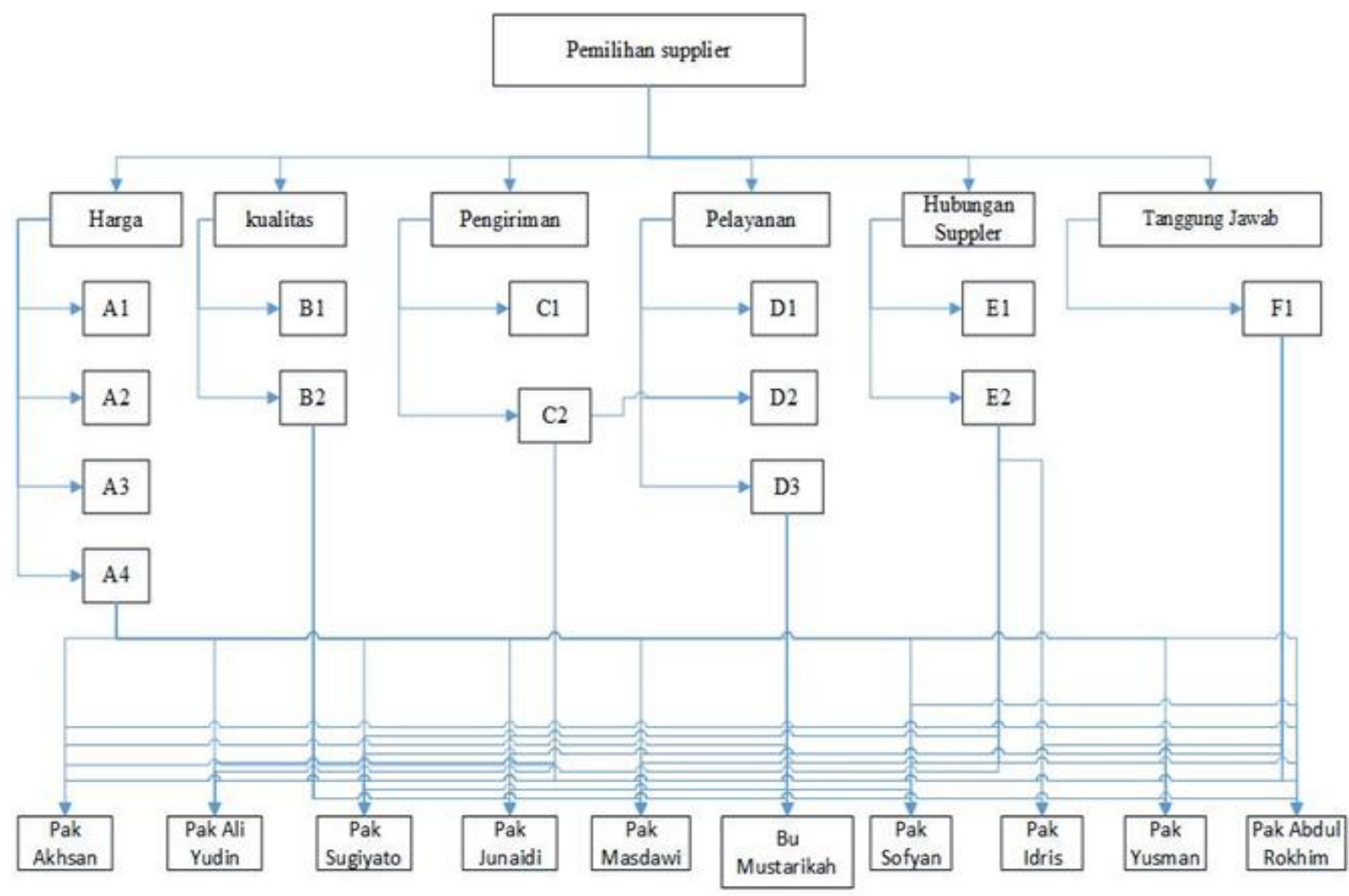

Gambar 2. Struktur Hirarki Masalah Pemilihan Supplier PT. Urchindize

Sumber: Data Primer (2019)

Penentuan Bobot dan Uji Konsistensi

1. Menghitung bobot atau prioritas dari masing-masing variabel pada level 1

Tabel 2. Rata-Rata Geometris kriteria

\begin{tabular}{|l|l|l|l|l|l|l|}
\hline \multirow{2}{*}{ Kriteria } & \multicolumn{6}{c|}{ Bobot } \\
\cline { 2 - 7 } & Harga & Kualitas & Pengiriman & Pelayanan & $\begin{array}{l}\text { Hubungan } \\
\text { Saupplier }\end{array}$ & $\begin{array}{c}\text { Tanggung } \\
\text { Jawab }\end{array}$ \\
\hline Responden 1 & 0,261 & 0,198 & 0,313 & 0,103 & 0,085 & 0,039 \\
\hline Responden 2 & 0,249 & 0,243 & 0,303 & 0,057 & 0,038 & 0,110 \\
\hline Responden 3 & 0,472 & 0,198 & 0,143 & 0,038 & 0,089 & 0,059 \\
\hline Responden 4 & 0,388 & 0,165 & 0,165 & 0,067 & 0,082 & 0,050 \\
\hline Responden 5 & 0,294 & 0,320 & 0,190 & 0,040 & 0,097 & 0,060 \\
\hline Responden 6 & 0,259 & 0,240 & 0,301 & 0,056 & 0,108 & 0,036 \\
\hline Responden 7 & 0,351 & 0,169 & 0,291 & 0,056 & 0,095 & 0,037 \\
\hline Responden 8 & 0,317 & 0,336 & 0,169 & 0,079 & 0,054 & 0,043 \\
\hline Responden 9 & 0,318 & 0,220 & 0,288 & 0,081 & 0,056 & 0,037 \\
\hline GM & 0,323 & 0,232 & 0,240 & 0,064 & 0,078 & 0,052 \\
\hline
\end{tabular}

Pada Tabel 2 menjelaskan bahwa kriteria harga menjadi prioritas dengan bobot sebesar 0,323 , prioritas kedua adalah pengiriman dengan bobot sebesar 0,240, prioritas ketiga adalah kualitas dengan bobot sebesar 0,232, prioritas keempat adalah
Hubungan Supplier dengan bobot sebesar 0,078 , prioritas kelima dan keenam adalah pelayanan dan tanggung jawab dengan bobot sebesar 0,064 dan 0,052 . 
2. Menghitung bobot atau prioritas dari masing-masing variabel pada level 2

Setelah didapatkan hasil perhitungan bobot dari masing-masing subkriteria, kemudian hasilnya bobot subkriteria akan dirata-rata menggunakan rata-rata geometris.

\section{a. Kriteria Harga}

Tabel 3. Rata-Rata Geometris Subkriteria pada Kriteria Harga

\begin{tabular}{|c|c|c|c|c|}
\hline & \multicolumn{4}{|c|}{ Bobot } \\
\hline Kriteria & \multicolumn{4}{|c|}{ Harga } \\
\hline Subkriteria & $\mathrm{A} 1$ & $\mathrm{~A} 2$ & $\mathrm{~A} 3$ & $\mathrm{~A} 4$ \\
\hline Responden 1 & 0,436 & 0,341 & 0,082 & 0,141 \\
\hline Responden 2 & 0,543 & 0,136 & 0,245 & 0,076 \\
\hline Responden 3 & 0,543 & 0,245 & 0,136 & 0,076 \\
\hline Responden 4 & 0,484 & 0,291 & 0,151 & 0,074 \\
\hline Responden 5 & 0,484 & 0,331 & 0,102 & 0,084 \\
\hline Responden 6 & 0,411 & 0,361 & 0,107 & 0,120 \\
\hline Responden 7 & 0,380 & 0,380 & 0,062 & 0,179 \\
\hline Responden 8 & 0,533 & 0,273 & 0,128 & 0,067 \\
\hline Responden 9 & 0,501 & 0,159 & 0,077 & 0,263 \\
\hline Total & 0,479 & 0,280 & 0,121 & 0,120 \\
\hline
\end{tabular}

Pada Tabel 3 menjelaskan bahwa harga produk mendapat prioritas pertama dengan bobot sebesar 0,479, Hal ini dapat diartikan bahwa harga pokok menjadi prioritas utama yang dilihat dari kriteria harga, prioritas kedua adalah kemauan bernegosiasi dengan bobot sebesar 0,280 , prioritas ketiga adalah cara pembayaran dengan bobot sebesar 0,121 dan prioritas terakhir adalah biaya transportasi dengan bobot sebesar 0,120.

\section{b. Kriteria Kualitas}

Tabel 4. Rata-Rata Geometris Subkriteria pada Kriteria Kualitas

\begin{tabular}{|l|l|l|}
\hline \multicolumn{3}{|c|}{ Bobot } \\
\hline Kriteria & \multicolumn{2}{|c|}{ Kualitas } \\
\hline Subkriteria & B1 & B2 \\
\hline Responden 1 & 0,875 & 0,125 \\
\hline Responden 2 & 0,125 & 0,875 \\
\hline Responden 3 & 0,25 & 0,75 \\
\hline Responden 4 & 0,125 & 0,875 \\
\hline Responden 5 & 0,75 & 0,25 \\
\hline Responden 6 & 1,25 & 0,417 \\
\hline Responden 7 & 0,834 & 0,167 \\
\hline Responden 8 & 0,834 & 0,167 \\
\hline Responden 9 & 0,25 & 0,75 \\
\hline Total & 0,588 & 0,486 \\
\hline
\end{tabular}

Pada Tabel 4 menjelaskan bahwa pada kriteria kualitas, subkriteria produk sesuai standar perusahaan menjadi prioritas utama dengan bobot sebesar 0,588 dan subkriteria kualitas bahan baku konsisten menjadi prioritas kedua dengan bobot sebesar 0,486.

\section{c. Kriteria Pengiriman}

Tabel 5. Rata-Rata Geometris Subkriteria pada Kriteria Pengiriman

\begin{tabular}{|c|c|c|}
\hline \multicolumn{3}{|c|}{ Bobot } \\
\hline Kriteria & \multicolumn{2}{|c|}{ Pengiriman } \\
\hline Subkriteria & C1 & C2 \\
\hline Responden 1 & 0,250 & 0,750 \\
\hline Responden 2 & 0,833 & 0,167 \\
\hline Responden 3 & 0,833 & 0,167 \\
\hline Responden 4 & 0,833 & 0,167 \\
\hline Responden 5 & 0,833 & 0,167 \\
\hline Responden 6 & 0,833 & 0,167 \\
\hline Responden 7 & 0,250 & 0,750 \\
\hline Responden 8 & 0,750 & 0,250 \\
\hline Responden 9 & 0,500 & 0,500 \\
\hline Total & 0,657 & 0,343 \\
\hline
\end{tabular}

Pada Tabel 5 menjelaskan bahwa pada kriteria pengiriman subkriteria ketepatan waktu pengiriman menjadi prioritas utama dengan bobot sebesar 0,657 dan proritas kedua adalah kesesuaian jumlah barang dengan bobot sebesar 0,343.

\section{d. Kriteria Pelayanan}

Tabel 6. Rata-Rata Geometris Subkriteria pada Kriteria Pelayanan

\begin{tabular}{|c|c|c|c|}
\hline & \multicolumn{3}{|c|}{ Bobot } \\
\hline Kriteria & \multicolumn{3}{|c|}{ Pelayanan } \\
\hline Subkriteria & D1 & D2 & D3 \\
\hline Responden 1 & 0,115 & 0,405 & 0,480 \\
\hline Responden 2 & 0,480 & 0,405 & 0,115 \\
\hline Responden 3 & 0,260 & 0,633 & 0,106 \\
\hline Responden 4 & 0,455 & 0,455 & 0,091 \\
\hline Responden 5 & 0,633 & 0,260 & 0,106 \\
\hline Responden 6 & 0,655 & 0,158 & 0,187 \\
\hline Responden 7 & 0,405 & 0,480 & 0,115 \\
\hline Responden 8 & 0,633 & 0,260 & 0,106 \\
\hline Responden 9 & 0,655 & 0,158 & 0,187 \\
\hline Total & 0,477 & 0,357 & 0,166 \\
\hline
\end{tabular}


Pada Tabel 6 menjelaskan bahwa pada kriteria pelayanan yang menjadi prioritas pertama adalah subkriteria cepat tanggap dalam menangani keluhan pembeli dengan bobot sebesar 0,477 , prioritas kedua adalah subkriteria kemudahan komunikasi dengan bobot sebesar 0,357 dan prioritas terakhir adalah subkriteria keramahan supplier 0,166.

\section{e. Kriteria Hubungan Supplier}

Tabel 7. Rata-Rata Geometris Subkriteria pada Kriteria Hubungan Supplier

\begin{tabular}{|l|l|l|}
\hline \multicolumn{3}{|l|}{ Bobot } \\
\hline Kriteria & \multicolumn{1}{l|}{ Hubungan Supplier } \\
\hline Subkriteria & E1 & E2 \\
\hline Responden 1 & 0,834 & 0,167 \\
\hline Responden 2 & 0,167 & 0,834 \\
\hline Responden 3 & 0,25 & 0,75 \\
\hline Responden 4 & 0,834 & 0,167 \\
\hline Responden 5 & 0,834 & 0,167 \\
\hline Responden 6 & 0,25 & 0,75 \\
\hline Responden 7 & 0,75 & 0,25 \\
\hline Responden 8 & 0,875 & 0,125 \\
\hline Responden 9 & 0,5 & 0,5 \\
\hline Total & 0,588 & 0,412 \\
\hline
\end{tabular}

Pada Tabel 7 menjelaskan bahwa pada kriteria pelayanan yang menjadi prioritas utama adalah subkriteria kinerja masa lalu dengan bobot sebesar 0,588 dan prioritas kedua adalah subkriteria kepercayaan kedua belah pihak dengan bobot sebesar 0,412.

\section{Menghitung bobot data dari masing- masing variabel pada level 3}

Proses menghitung bobot dan menguji konsistensi data dari masing-masing variabel pada level 3 (alternative) yaitu bobot setiap supplier dibandingkan dengan masing-masing subkriteria. Alternative yang dibandingkan ada 10 alternative diantaranya adalah:
A = Pak Akhsan
$\mathrm{F}=\mathrm{Bu}$ Mustarikah
$\mathrm{B}=$ Pak Ali Yudin
$G=$ Pak Sofyan
$\mathrm{C}=$ Pak Sugiyanto $\mathrm{H}=$ Pak Idris
$\mathrm{D}=$ Pak Junaidi $\quad \mathrm{I}=$ Pak Yusman
$\mathrm{E}=$ Pak Masdawi $\mathrm{J}=$ Pak Abdul Rokhim

Bedasarkan hasil pengolahan data pada masing-masing subkriteria menjelaskan bahwa pada subkriteria A1 supplier B yang menjadi prioritas utama dengan bobot sebesar 0,209, sedangkan pada subkriteria A2 supplier B yang menjadi prioritas utama dengan bobot sebesar 0,175 , sedangkan pada subkriteria $A 3$ supplier B yang menjadi prioritas utama dengan bobot sebesar 0,174 , sedangkan pada subkriteria A4 supplier A yang menjadi prioritas utama dengan bobot sebesar 0,151, sedangkan pada subkriteria B1 supplier B yang menjadi prioritas utama dengan bobot sebesar 0,198, sedangkan pada subkriteria B2 supplier B yang menjadi prioritas utama dengan bobot sebesar 0,175 , sedangkan pada subkriteria C1 supplier B yang menjadi prioritas utama dengan bobot sebesar 0,182, sedangkan pada subkriteria A2 supplier C yang menjadi prioritas utama dengan bobot sebesar 0,166, sedangkan pada subkriteria D1 supplier B yang menjadi prioritas utama dengan bobot sebesar 0,188 , sedangkan pada subkriteria D2 supplier A yang menjadi prioritas utama dengan bobot sebesar 0,157, sedangkan pada subkriteria D3 supplier B yang menjadi prioritas utama dengan bobot sebesar 0,168 , sedangkan pada subkriteria E1 supplier B yang menjadi prioritas utama dengan bobot sebesar 0,163 , sedangkan pada subkriteria E2 supplier B yang menjadi prioritas utama dengan bobot sebesar 0,171 dan pada subkriteria F1 supplier A yang menjadi prioritas utama dengan bobot sebesar 0,180 .

\section{Pengambilan Keputusan}

Setelah hasil bobot dari masing-masing kriteria, subkriteria dan alternative didapatkan kemudian di cari nilai alternative weight dari masing-masing supplier. Alternative weight didapatkan dari perkalian antara nilai setiap attribute weight dengan eigen vector atau bobot dan dijumlahkan hasilnya dari setiap kriteria.

Berdasarkan hasil pengolahan data dengan metode Analytical Hierarchy Process (AHP), nilai bobot tiap supplier menjelaskan bahwa supplier yang jadi pilihan supplier utama adalah supplier Pak Ali Yudin berarti supplier Pak Ali Yudin mampu menjadi supplier terbaik bagi perusahaan. Hal ini dibuktikan pada keseluruhan sub kriteria dengan bobot sebesar 0,181 , supplier $A$ yaitu Pak Akhsan dengan bobot sebesar 0,159, supplier $C$ yaitu Pak Sugiyanto dengan bobot 
sebesar 0,141 , supplier $D$ yaitu Pak Junaidi dengan bobot sebesar 0,118 , supplier $E$ yaitu Pak Masdawi dengan bobot sebesar 0,102, supplier F yaitu Bu Mustarikah dengan bobot sebesar 0,081 , supplier $G$ dan $H$ yaitu Pak Sofyan dan Pak Idris dengan bobot sebesar 0,073, supplier I yaitu Pak Yusman dan supplier J yaitu Pak Abdul Rokhman dengan bobot sebesar 0,044 dan 0,037.

\section{SIMPULAN}

Berdasarkan hasil pengolahan data menggunakan metode AHP, sehingga dapat diambil kesimpulan:

1. Karakteristik pemilihan supplier oleh PT. Urchindize ini berdasarkan pada kontinuitas supplier dalam pengiriman bahan baku kepada perusahaan. Berdasarkan kontinuitas supplier dalam mengirimkan bahan baku maka di dapatkan 10 supplier diantaranya: Pak Akhsan, Pak Ali Yudin, Pak Sugiyanto, Pak Junaidi, Pak Masdawi, Bu Mustarikah, Pak Sofyan, Pak Idris, Pak Yusman, Pak Abdul Rokhim.

2. Berdasarkan hasil pengolahan data dengan menggunakan metode Analytical Hierarchy Process (AHP), didapatkan hasil sebagai beririkut:

a. Kriteria yang paling berpengaruh dalam pemilihan supplier ikan teri pada PT. Urchindize adalah kriteria harga dengan bobot sebesar 0,323. Prioritas kedua yang berpengaruh adalah kriteria pengiriman dengan bobot sebesar 0,24. Prioritas ketiga adalah kriteria kualitas dengan bobot sebesar 0,232. Prioritas keempat adalah kriteria hubungan supplier dengan bobot sebesar 0,078, sedangkan prioritas kelima dan keenam adalah kriteria pelayanan dan tanggung jawab dengan bobot sebesar 0,064 dan 0,052.

b. Supplier yang tepat yang harus di pilih oleh PT. Urchindize sebagai pemasok ikan teri yaitu Pak Ali Yudin menjadi prioritas utama dengan bobot sebesar 0,181, kedua adalah Pak Akhsan dengan bobot sebesar 0,159, ketiga adalah Pak Sugiyanto dengan bobot sebesar 0,141, keempat adalah Pak
Junaidi dengan bobot sebesar 0,118 , kelima adalah Pak Masdawi dengan bobot sebesar 0,102 , keenam adalah bu Mustarikah dengan bobot sebesar 0,081 , ketujuh adalah Pak Sofyan dan Pak Idris dengan bobot sebesar 0,073, kedelapan adalah Pak Yusman dengan bobot sebesar 0,044 , prioritas terakhir adalah Pak Abdul Rokhman dengan bobot sebesar 0,037.

\section{DAFTAR PUSTAKA}

Bintang Pamungkas, Diyat. (2017). Penentuan Supplier Bahan Cat Mobil Dengan Pendekatan Analytical Hierarchy Process (AHP) (Studi Kasus: Bengkel Body Repair "Ketos"). Yogyakarta: Fakultas Teknologi Industri Universitas Islam Indonesia.

Heizer, Jay end Barry Render. (2015). Manejemen Oprasi: Manejemen keberlangsungan dan rantai pasokan,edisi sebelas. Terjemahan: Hirson kurnia dkk. Jakarta: Salemba Empat.

Inda Windriya, Salma. (2018). Evaluasi Pemilihan Supplier Pada Retail Pamella 6 Supermarket di Yogyakarta. Yogyakarta: Fakultas Ekonomi Universitas Islam Indonesia.

Indrajit, Eko Richardus dan Richardus Djokopranoto. (2016). Supply Chain Management, edisi Kedua.Yogyakarta: Preinexus.

Kuntara Saputra, Tio. (2018). Penentuan Kriteria Dalam Pemilihan Supplier Bahan Kain Pada Industri Textile Dengan Menggunakan Metode Analytical Hierarchy Process (AHP). Yogyakarta: Fakultas Teknologi Industri Universitas Islam Indonesia.

Pujawan, I.N. dan M Erawan. (2010). Supply Chain Management, edisi kedua. Surabaya: Guna Widya Press.

Rahmayanti, Reny. (2010). Analisis Pemilihan Supplier Menggunakan Metode Analytical Hierarchy Process (AHP) (Studi Kasus Pada Pt Cazikhal). Surakarta: Fakultas Ekonomi Universitas Sebelas Maret.

Saaty, Thomas L end Luis G. Vargas. (2012). Models, Methods, Concepts \& 
Applications of the Analytic Hierarchy

Process, $2^{\text {th }}$ ed. New York: Springer US 